3. Барбиков Д.В., Андрейко С.С., Иванов О.В., Бобров Д.А. Оценка газодинамических характеристик горных пород Краснослободского разлома // Горн. журн. - 2018. - № 8. - С. 38-42.

4. Андрейко С.С. Газодинамические явления в калийных рудниках: методы прогнозирования и способы предотвращения: учеб. пособие / С.С. Андрейко. - Пермь: Изд-во. ПГТУ, 2007. - 208 с.

5. Андрейко С.С., Иванов О.В., Литвиновская Н.А. Прогнозирование и предотвращение газодинамических явлений из почвы при проходке подготовительных выработок в подработанном массиве соляных пород / С.С. Андрейко,. - Пермь: изд-во ПНИПУ, 2015. - 159 с.

6. Земсков А.Н., Кондрашев П.И., Травникова Л.Г. Природные газы калийных месторождений и меры борьбы с ними. - Пермь: Тип. Купца Тарасова, 2008. - 412 с.: ил., табл.

УДК 622.831

DOI: $10.7242 /$ echo.2019.2.20

\title{
СОВРЕМЕННОЕ СОСТОЯНИЕ ПРОБЛЕМЫ ГАЗОДИНАМИЧЕСКИХ ЯВЛЕНИЙ НА ДЕЙСТВУЮЩИХ И ВВОДИМЫХ В ЭКСПЛУАТАЦИЮ КАЛИЙНЫХ РУДНИКАХ
}

\author{
С.С. АНДРЕЙКО \\ Горный институт УрО РАН, г. Пермь
}

\begin{abstract}
Аннотация: Выполнен анализ современного состояния проблемы газодинамических явлений при подземной разработке калийных пластов камерной и столбовой системами разработки в условиях Верхнекамского, Гремячинского и Старобинского месторождений калийных солей. Выполнен анализ геологических и горнотехнических условий проявления выбросов соли и газа и приведены рекомендации по безопасному ведению подготовительных горных работ по пласту В карналлитового состава в выбросоопасных зонах аномального строения. Для условий шахтного поля рудника ООО «ЕвроХим-Усольский калийный комбинат» разработан комплекс мероприятий, направленных на предотвращение газодинамических явлений при ведении подготовительных и очистных горных работ в сложных горногеологических условиях. На основании анализа причин внезапного выброса соли и газа на Старобинском месторождении калийных солей разработаны мероприятия по предотвращению газодинамических явлений при выемке сильвинитового слоя 4 пласта III калийного горизонта через длительный (не менее 25 лет) промежуток времени после подработки его лавой по слоям 2, 2-3 и 3 Третьего калийного пласта. На Гремячинском месторождении калийных солей в результате изучения случаев разрушений приконтурной части выработок в процессе проходки комбайновыми комплексами выявлены общие признаки, характерные для газодинамических явлений в виде внезапных выбросов соли и газа. На основании представленных признаков внезапные разрушения приконтурной части пород следует классифицировать как внезапные выбросы соли и газа и горные работы при вскрытии и пересечении слоя карналлит-галитовой породы необходимо вести в соответствии с требованиями нормативной документации по безопасному ведению горных работ.

Ключевые слова: газодинамические явления; месторождения калийных солей; камерная система разработки; столбовая система разработки; подготовительные выработки; внезапные выбросы соли и газа; геологические и горнотехнические условия; мероприятия; рекомендации.
\end{abstract}

В настоящее время, как показывает практика ведения горных работ на калийных пластах, опасных по газодинамическим явлениям, решена значительная часть вопросов, связанных с прогнозированием и предотвращением внезапных газодинамических явлений (ГДЯ). Для условий рудников ПАО «Уралкалий» и ОАО «Беларуськалий» разработаны и внедрены эффективные методы контроля предупредительных признаков и предвестников ГДЯ, региональные, локальные и текущие методы прогнозирования, а также эффективные способы предотвращения известных видов газодинамических явлений [1-10]. В тоже время следует отметить, что, несмотря на достигнутые существенные успехи в решении данной проблемы, ГДЯ продолжают происходить. Это связано с двумя основными причинами: человеческим фактором и вовлечением в отработку новых шахтных полей калийных рудников, для условий которых параметры профилактических мероприятий принимались методом аналогии без учета специфики геологического строения разрабатываемых пластов и вмещающих пород и согласования со специализированными организациями. 
В этой связи исследования геологических условий образования очагов газодинамических явлений, механизма их протекания при техногенном воздействии на газонасыщенный массив, разработка надежных методов прогнозирования и эффективных способов предотвращения различных видов ГДЯ продолжаются и в настоящее время [11-21].

Наименее остро в последние два года проблема газодинамических явлений стоит на рудниках ПАО «Уралкалий», где газодинамические явления происходили только при ведении подготовительных горных работ на пласте В карналлитового состава. Для условий рудника СКРУ-1 проводились исследования по научному сопровождению подготовительных горных работ на карналлитовом пласте В в условиях 5 восточной панели. В процессе проходки уклона на пласт В и выемочного штрека на 5 восточной панели рудника СКРУ-1 ПАО «Уралкалий» в апреле 2017 г. была вскрыта зона, где пласт В содержит крупные (от 30 см до 5 м и более) блоки каменной соли неясной природы, которые значительно изменили конфигурацию промышленного пласта. Проведение буровзрывных работ по приведению кровли в безопасное состояние в выемочном штреке привели к инициированному выбросу соли и газа, в результате которого в районе камер №№36-38 образовалась куполовидной полости высотой более 8 м. Для разработки мероприятий по дальнейшему безопасному ведению горных работ по пласту В на 5 восточной панели был выполнен анализ геологических условий ведения горных работ на 5 восточной панели [19].

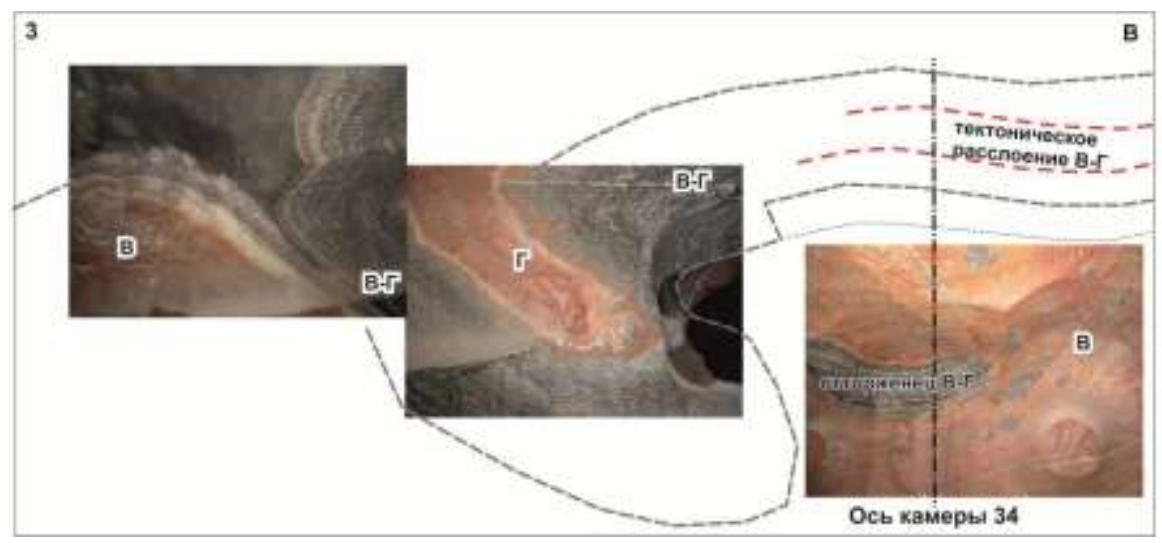

Рис. 1. Геологическое строения пластов В, В-Г и Г на выемочном штреке 5 восточной панели (район камеры № 34) [22]

При структурногеологическом обследовании места выброса соли и газа на пласте $\mathrm{B}$, а также выемочного штрека на 5 восточной панели выемочного штрека были установлены следующие факты. Выемочным штреком на 5 восточной панели в районе камеры № 34 была вскрыта высокоамплитудная (до 7 м), падающая на запад, синклинальная складка, в ядре которой был вскрыт пласт $\Gamma$ (рисунок 1).

Кроме этого было установлено, что восточнее камеры № 34 до уклона, вскрывающего пласт В включительно, породы междупластья В-Г разорваны, раздроблены и расслоены за счет интенсивной складчатости. При этом междупластье В-Г погружено в карналлиты пласта В, а мощность отдельных блоков пород междупластья В-Г («плавающих отторженцев»), погруженных в карналлиты пласта В, составляет до 1 м, а площадь - до нескольких десятков метров [22]. В процессе проходки уклона на пласт В в районе камер №№ 43-45 на 5 восточной панели было вскрыто продолжение зоны геологического нарушения, вскрытого ранее в западной части 5 восточной панели. При торпедировании забоя уклона буровзрывными работами произошел инициированный выброс соли и газа. Обследование полости выброса соли и газа показало, что в пласте В находятся крупные блоки пород междупластья В-Г, выше которых пласт полностью потерял свое слоистое строение и превращен в карналлитовую брекчию (рисунок 2). Вблизи полости выброса соли и газа установлены крупные локальные участки перекристаллизации карналлита бело-желтого цвета, к которым приурочены современные сдвиговые нарушения, разделяющие участки с различной ориентировкой кливажа и выполненные карналлитовой «мукой». 


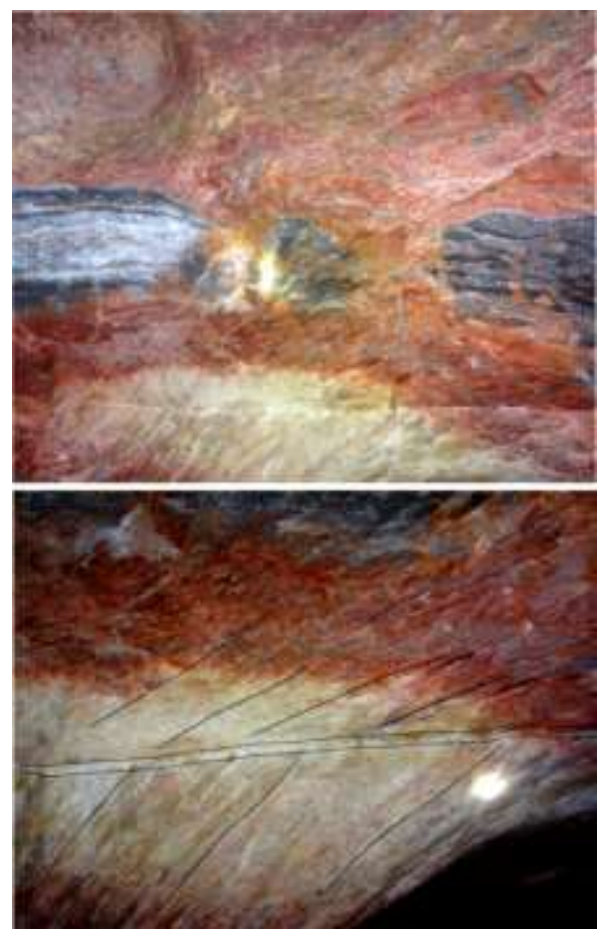

Рис. 2. Зона брекчирования пород пласта В (вверху) и трещины кливажа вблизи полости выброса соли и газа (внизу) [22]

Структурный анализ поверхности пласта В в месте выброса соли и газа свидетельствует о том, что выброс соли и газа из пород кровли приурочен к узкой субмеридиональной синклинальной складке. Выброс соли и газа из кровли при ведении горных пород на пласте В вызван следующими причинами: наличием в кровле выемочного штрека ослабленных и расслоившихся пород пласта каменной соли В-Г, выполняющего при отработке пласта В функцию защитной пачки, и газоносного пласта Г; наличием разрывов пласта В-Г в месте газодинамического явления, способствующих формированию очаговых скоплений свободных газов; взрывным воздействием на породы кровли при мгновенном взрывании зарядов ВВ при оборке кровли в месте газодинамического явления. Для дальнейшего безопасного ведения горных работ по пласту В на 5 восточной панели рудника СКРУ-1 был разработан следующий комплекс мероприятий включающий: оконтуривание зоны аномального строения пласта В на 5 восточной панели; ведение горных работ в пределах зоны аномального строения пласта В в полуавтоматическом (дистанционном) режиме управления комбайном только в присугствии лица технического надзора участка; отработку очистных камер по пласту $\mathrm{B}_{\kappa}$ на 5 восточной панели в пределах зоны дробления не производить; при проходке подготовительных и других выработок в пределах зоны дробления на 5 восточной панели при оборке кровли буровзрывным способом в месте оборки должно производиться бурение глубоких дегазационных шпуров в кровлю со следующими параметрами: глубина шпуров - не менее 6 м; расстояние между шпурами не более 2,5 м. При взрывании зарядов ВВ в шпурах для оборки кровли для уменьшения сейсмического воздействия на породы кровли должно применяться короткозамедленное взрывание с интервалом замедления не менее 30 мс; для предотвращения режима сотрясательного взрывания при торпедировании пласта В при взрывании зарядов ВВ применять не менее двух ступеней короткозамедленного взрывания с интервалом замедления не менее 30 мс. На других рудниках ПАО «Уралкалий» при отработке сильвинитовых пластов $\mathrm{B}_{c}$, АБ и КрII газодинамические явления в 2017 2018 гг. не происходили.

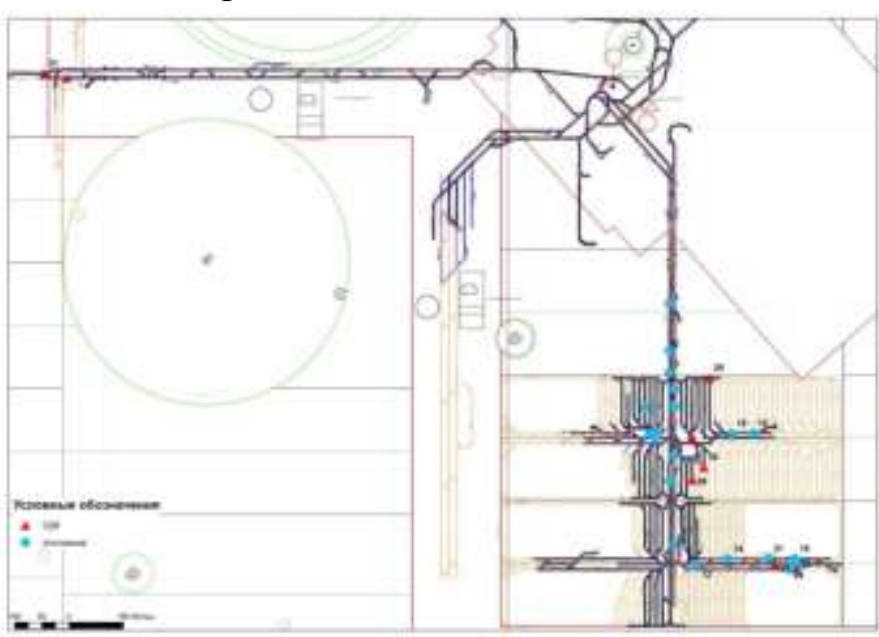

Рис. 3. Газодинамические явления на шахтном поле рудника Усольского ГОКа
В настоящее время горноподготовительные работы ведутся на руднике ООО «ЕвроХим-Усольский калийный комбинат». Здесь проблема ГДЯ стоит наиболее остро - всего при ведении горно-подготовительных работ по пласту КрII произошло 8 газодинамических явлений в виде внезапных обрушений пород кровли, сопровождающихся газовыделением, и явлений комбинированного типа (рисунок 3).

Горнотехническая ситуация, сложившаяся на руднике ООО «ЕвроХим-Усольский калийный комбинат», 
потребовала экстренной разработки комплекса мероприятий по пред-отвращению газодинамических явлений при ведении горно-подготовительных работ. На основании анализа геологических и горнотех-нических условий проявления ГДЯ был разработан комплекс мер, направленных на предотвращение газодинамических явлений при ведении подготовительных и очистных горных работ в сложных горно-геологических условиях рудника ООО «ЕвроХимУсольский калийный комбинат». Комплекс мероприятий по предотвращению газодинамических явлений при ведении подготовительных и очистных горных работ в сложных горногеологических условиях рудника ООО «ЕвроХим-Усольский калийный комбинат» предусматривает: корректировку параметров мелкошпурового и глубокого профилактического бурения дегазационных шпуров в кровлю горных выработок в части увеличения глубины шпуров и уменьшения расстояния между шпурами, что отражено в «Паспорте профилактического и защитного бурения дегазационных шпуров»; предварительную дегазацию пород кровли горных выработок в местах разделки сопряжений горных выработок шпурами и скважинами с помощью буровых установок; снижение количества сопряжений (расширений) горных выработок по пласту КрІІ до минимально необходимого с учетом технологической целесообразности; приобретение дополнительного количества самоходного бурового оборудования для бурения глубоких дегазационных шпуров и скважин, обеспечения опережающих геологоразведочных и научно-исследовательских работ по оценке газодинамической опасности соляного породного массива; применение в условиях шахтного поля рудника ООО «ЕвроХимУсольский калийный комбинат» проходческо-очистных комбайнов типа «Урал-61А», позволяющих снизить пролет выработок до 3,0 м и, соответственно, уменьшить вероятность возникновения газодинамических явлений из кровли горных выработок. В настоящее время весь комплекс мероприятий внедрен на руднике ООО «ЕвроХим-Усольский калийный комбинат» и случаев газодинамических явлений больше не отмечалось.

На руднике 3 РУ ОАО «Беларуськалий» 9 марта 2018 года на подземном горном участке № 10 при выполнении проходческим комплексом ПКС-8 №4 зарубки на технологическую сбойку №22-б западного столба горизонта -620 м произошел внезапный выброс соли и газа. Интенсивность внезапного выброса соли и газа составила порядка $600 \mathrm{~m}^{3}$ горной массы. Проходческий комбайн и самоходный вагон оказались полностью засыпаны выброшенной породой, погибли машинист горных выемочных машин и горнорабочий очистного забоя. На основании результатов расследования причин данной аварии были разработаны мероприятия по предотвращению газодинамических явлений при выемке сильвинитового слоя 4 пласта III калийного горизонта через длительный (не менее 25 лет) промежуток времени после подработки его лавой по слоям 2, 2-3 и 3 Третьего калийного пласта. Внедрить предлагается следующие мероприятия:

- исключить проходку подготовительных выработок в межпанельных (межстолбовых) целиках при реализации технологической схемы столбовой системы разработки класса 10. При невозможности исключения необходимо минимизировать количество проходимых в межпанельных целиках подготовительных горных выработок, сопряжений, перерубок и камер;

- перед началом проходки подготовительных выработок в межпанельных целиках проводить обследование методом сейсмической томографии для выявления выбросоопасных геологических нарушений - мульд погружения. При невозможности обследования методом сейсмической томографии всего межпанельного целика (отсутствие действующих выработок для реализации метода) допускается его обследование только на участках проходки подготовительных выработок - технологических сбоек различного назначения;

- при проходке подготовительных выработок в межпанельных целиках, кровля которых расположена в слоях 3 и 3-4, при появлении локального прогиба слоев на стенках выработки при углах погружения слоев 2 и 3 от $5^{\circ}$ до $15^{\circ}$ производить уточнение строения массива пород на данном участке выработки. Уточнение строения массива пород на участке локального прогиба слоев может производиться: методом сейсмической томографии при возможности его реализации; бурением наклонной геологоразведочной скважины с отбором керна глубиной - 
до перебуривания глинисто-карналлитового пласта на полную мощность; подрубкой стенки выработки комбайном в полуавтоматическом (дистанционном) режиме управления на глубину до 1,0 м с предварительным бурением по центру прогиба глубокой наклонной $\left(25^{\circ}-30^{\circ} \mathrm{\kappa}\right.$ вертикали) дегазационной скважины глубиной - до перебуривания глинисто-карналлитового пласта на полную мощность; буровзрывным способом.

- запретить разделку сопряжений, расширений и проходка технологических сбоек на расстоянии менее 50 м от установленных локальных прогибов слоев до уточнения строения массива пород в месте локального прогиба;

- при проходке подготовительных горных выработок в межпанельных целиках применять бурение шпуров в кровлю этих выработок: мелкошпуровое профилактическое бурение дегазационных шпуров и профилактическое бурение глубоких дегазационных шпуров (глубокое профилактическое бурение). Параметры мелкошпурового профилактического бурения: для выработок, кровля которых расположена в слое 3 и 3-4, в кровлю бурятся шпуры глубиной не менее 1,2 м, с шагом не более чем через 2,5 м вдоль выработки по мере проходки. Параметры глубокого профилактического бурения: в выработках, проходимых по технологической схеме №10 с привязкой кровли в слоях 3 и 3-4, независимо от их ширины производится бурение глубоких дегазационных шпуров глубиной не менее 6,0 м и шагом бурения не более 5,0 м во время проходки с использованием буровой колонки, расположенной на комбайне;

- в местах разделки сопряжений с технологическими сбойками, камерами и перерубками до начала их проходки должны быть пробурены 3 ряда глубоких дегазационных скважин из 3 скважин со следующими параметрами: первый ряд скважин бурится в начале зарубки комбайна - одна скважина вертикальная по центру выработки; две скважины наклонные под углом $25^{\circ}-30^{\circ}$ к вертикали на расстоянии от вертикальной скважины в стороны 1,0 м; третий ряд дегазационных скважин с теми же параметрами бурится на уровне предполагаемого «утюга»; второй ряд дегазационных скважин с теми же параметрами бурится на расстоянии от «утюга» не более 3,0 м; вертикальные и наклонные скважины бурятся глубиной, обеспечивающей перебуривание глинисто-карналлитового пласта на полную мощность. При проходке подготовительных выработок «в присечку» к выработанному пространству в рядах дегазационных скважин наклонные скважины бурятся только в направлении массива пород.

В настоящее время на руднике Гремячинского горно-обогатительного комбината ООО «ЕвроХим-ВолгаКалий» при ведении горно-подготовительных работ по промышленному сильвинитовому пласту возникают проблемы, связанные с необходимостью вскрытия и пересечения забоем выработки карналлит-галитовый слоя пласта калийно-магниевых солей.
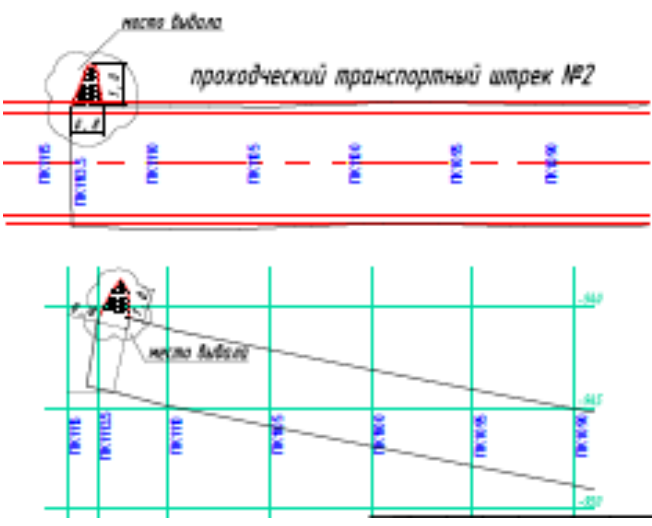

Рис. 4. Внезапный выброс соли и газа при проходке проходческого транспортного штрека № 2 комбайновым комплексом «Урал-20Р» по сильвинитовому пласту

с подрубкой карналлит-галитового слоя в правой стенке (рудник Гремячинского ГОКа ООО «ЕвроХим-ВолгаКалий»)
Как правило, такие горнотехнические ситуации приурочены к антиклинальным складкам пласта калийномагниевых солей. В таких горно-технических ситуациях происходят газодинамические явления в виде внезапных выбросов соли и газа (рисунок 4).

При этом следует отметить, что техническими службами рудника такие газодинамические явления классифицируются как вывалы горной массы, что абсолютно неправильно. Для того чтобы обоснованно приме- 
нять методы прогнозирования и способы предотвращения газодинамических явлений необходимо определиться для какого вида явлений необходимо разрабатывать методы прогнозирования и с каким видом ГДЯ необходимо бороться [23]. Критерии классификации ГДЯ на виды должны отражать причинность явлений и позволять по условиям возникновения, протекания и результатам закончившегося процесса разрушения приконтурной части выработки определять его вид и оценивать основные причины возникновения. В настоящее время для условий шахтного поля рудника Гремячинского ГОКа отсутствуют количественные критерии классификации газодинамических явлений. Такие критерии могут быть разработаны при наличии представительной выборки по видам газодинамических явлений, которая в настоящее время отсутствует. В этой связи вид происшедших разрушений приконтурной части пород при проходке выработок определялся по условиям возникновения, протекания и результатам закончившегося процесса разрушения на основании показаний очевидцев и фактов, изложенных в Актах, а также визуального осмотра мест разрушений непосредственно в горных выработках.

В результате анализа случаев разрушений приконтурной части выработок в процессе их проходки комбайновым комплексом «Урал-20Р» выявлены следующие общие признаки, характерные для ГДЯ в виде внезапных выбросов соли и газа:

- локальность проявления внезапных разрушений приконтурной части пород, которые приурочены к газоносному карналлит-галитовому слою;

- концентрация горючих газов в забое горной выработки во всех случаях после внезапного разрушения превышающая ПДК (содержание метана до 4\% при работающем ВМП);

- внезапность и высокая скорость разрушений приконтурной части пород (ни одном из случаев не было отмечено предвестников разрушений - прогибов кровли, отслоений боков, образование трещин в кровле и боках выработок);

-наличие полостей разрушения приконтурного массива и формы полостей внезапных разрушений, которые имеют произвольную форму с округлыми стенками (рисунок 5);

- стенки полостей разбиты концентрическими трещинами;

- характер разрушения карналлит-галитовой породы: порода представлена мелкими фракциями и тонкими пластинками, а также выпукло-вогнутыми пластинами, оконтуривающими полости, что свидетельствует о разрушении приконтурной части пород по механизму послойного отрыва, характерного только для выбросов соли и газа.

На основании представленных фактов внезапные разрушения приконтурной части пород, происшедшие при проходке горных выработок комбайном «Урал-20Р» по карналлитгалитовому слою на руднике Гремячинского ГОКа, следует классифицировать как внезапные выбросы соли и газа и горные работы при вскрытии слоя карналлит-галитовой породы необходимо вести в соответствии с требованиями нормативной документации по безопасному ве-

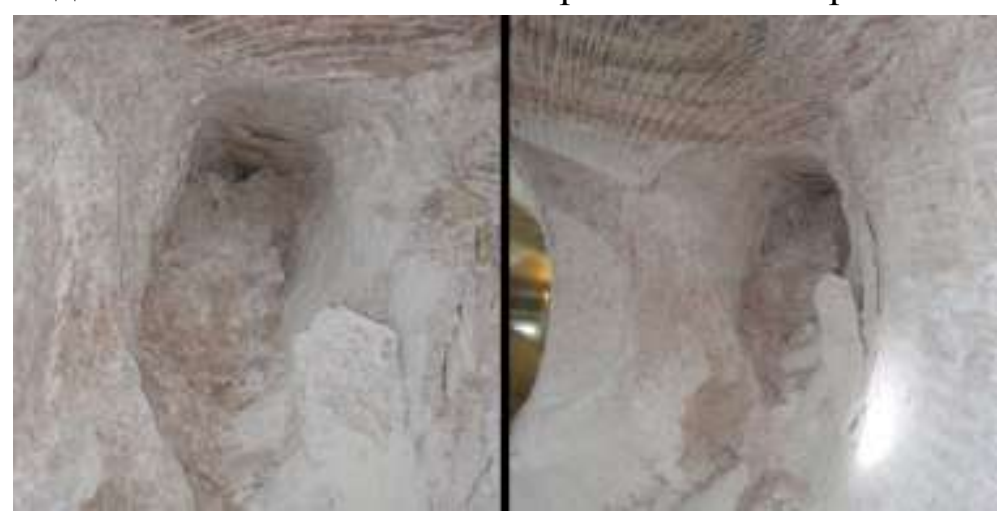

Рис. 5. Характерные полости выбросов соли и газа в стенке разведочного штрека № 2 (рудник Гремячинского ГОКа ООО «ЕвроХим-ВолгаКалий») дению горных работ - «Технологического регламента...».

В целом на основании анализа современное состояние проблемы газодинамических явлений на действующих и вводимых в эксплуатацию калийных рудниках в условиях Верхнекамского, Старобинского и Гремячинского месторождений калийных солей можно сделать следующие выводы:

- действующие и вводимые в эксплуатацию калийные руд- 
ники на всех разрабатываемых месторождениях обеспечены нормативной документацией, регламентирующей безопасное ведение горных работ на пластах, опасных по газодинамическим явлениям;

- газодинамические явления в калийных рудниках в настоящее время происходят по следующим причинам: в результате нарушения или неисполнения требований нормативных документов (Инструкций, Специальных мероприятий и Технологических регламентов), регламентирующих безопасное ведение горных работ на пластах, опасных по газодинамическим явлениям; ведения горных работ в геологических условиях, не нашедших отражения в нормативных документах в части параметров безопасного ведения горных работ и действий персонала в данных условиях;

- на основании анализа случаев газодинамических явлений в условиях Верхнекамского и Старобинского месторождений калийных солей разработаны мероприятия по предотвращению газодинамических явлений в условиях, где требуется разработка корректировка или уточнение параметров безопасного ведения горных работ на пластах, опасных по газодинамическим явлениям.

\section{Исследование выполнено при финансовой поддержке РФФИ в рамках} научного проекта № 18-05-00371 а «Газодинамические явления на калийных рудниках: внезапные разрушения кровли и почвы выработок»

\section{БИБЛИОГРАФИЧЕСКИЙ СПИСОК}

1. Андрейко С.С. Проблемы безопасной разработки калийных пластов: цели, тенденции и результаты // Моделирование стратегии и процессов освоения георесурсов: материалы междунар. конф. и науч. сес. ГИ УрО РАН. - Пермь, 2003. - С. 115-118..

2. Андрейко С.С. Результаты исследований по прогнозированию и предотвращению газодинамических явлений на Верхнекамском и Старобинском месторождениях калийных солей // Стратегия и процессы освоения георесурсов: материалы ежегод. науч. сес. ГИ УрО РАН по результатам НИР в 2006 г. - Пермь, 2007. - С. 137-139. 3. Андрейко С.С., Иванов О.В., Нестеров Е.А. Борьба с газодинамическими явлениями при разработке Верхнекамского и Старобинского месторождений калийных солей // Науч. исслед. и инновации. - 2009. - Т. 3, № 4. - С. 34-37.

4. Андрейко С.С. Современное состояние проблемы газодинамических явлений на Верхнекамском месторождении калийных солей // Стратегия и процессы освоения георесурсов: материалы ежегод. науч. сес. ГИ УрО РАН по результатам НИР в 2009 г. - Пермь, 2010. - С. 211-213.

5. Андрейко С.С., Перминов К.М. Разработка технологии добычи калийной руды с применением изгибающегося конвейерного поезда // Изв. вузов. Горн. журн. - 2013. - № 3. - С. 4-9.

6. Андрейко С.С., Литвиновская Н.А. Локальный прогноз зон, опасных по газодинамическим явлениям из почвы горных выработок пласта АБ на южной части шахтного поля БКПРУ-4 Верхнекамского месторождения калийных солей // Горн. информ.-аналит. бюл. - 2013. - № 4. - С. 205-211.

7. Андрейко С.С., Иванов О.В., Нестеров Е.А., Головатый И.И., Береснев С.П. Исследование газоносности соляных пород третьего калийного пласта на шахтном поле Краснослободского рудника // Горн. журн. - 2013. - № 6. - С. 69-73.

8. Тараканов В.А., Головатый И.И., Береснев С.П., Андрейко С.С., Иванов О.В. Исследование газоносности пород пласта третьего калийного горизонта Старобинского месторождения // Горн. журн. - 2010. - № 8. - С.25-27.

9. Подлесный И.А., Береснев С.П., Андрейко С.С., Некрасов С.В., Литвиновская Н.А. Геомеханическое моделирование внезапных разрушений пород почвы горных выработок // Горн. журн. - 2010. - № 8. - С.28-30.

10. Береснев С.П., Сенюк В.В., Гончар В.И., Андрейко С.С., Литвиновская Н.А. Исследование механизма формирования опасных по газодинамическим явлениям зон в породах калийного горизонта // Горн. журн. - 2010. - № 8. - С.31-33.

11. Марков О.И., Береснев С.П., Петровский Ю.Б., Андрейко С.С., Мальцев В.М. Параметры буровзрывного инициирования выбросов соли и газа при пересечении выбросоопасных геологических нарушений // Горн. журн. - 2010. - № 8. - С.75-77.

12. Андрейко С.С., Иванов О.В., Нестеров Е.А., Литвиновская Н.А. Исследование газоносности продуктивных калийных пластов на новых участках шахтных полей калийных рудников ОАО «Уралкалий и ОАО «Сильвинит» // Горн. информ.-аналит. бюл. - 2010. - № 4. - С. 186-190.

13. Андрейко С.С., Иванов О.В., Бикмаева Т.А. Разработка математической модели метода прогнозирования внезапных разрушений пород почвы горных выработок при очистной выемке карналлитового пласта в условиях Верхнекамского месторождения калийных солей // Горн. информ.-аналит. бюл. - 2010. - № 4. - С. 191-196. 
14. Андрейко С.С., Иванов О.В., Нестеров Е.А. Борьба с газодинамическими явлениями при разработке Верхнекамского и Старобинского месторождений калийных солей // Науч. исслед. и инновации. - 2009. - Т. 3, № 4. - С. $34-37$.

15. Нестеров Е.А., Иванов О.В., Андрейко С.С. Газоносность калийных пород по связанным газам в условиях Краснослободского рудника // Науч. исслед. и инновации. - 2010. - Т. 4, № 1. - С. 89-91.

16. Андрейко С.С., Иванов О.В. Метод прогноза газодинамических явлений при разработке сильвинитовых пластов Верхнекамского месторождения калийных солей // Горн. информ.-аналит. бюл. - 2009. - № 7. - С. 368-373.

17. Нестеров Е.А. Исследование газодинамической опасности пород III калийного горизонта шахтного поля вводимого в эксплуатацию Краснослободского рудника 2РУ ОАО «Беларуськалий» // Стратегия и процессы освоения георесурсов: сб. науч. тр. Вып. 10 / ГИ УрО РАН. - Пермь, 2012. - С. 232-234.

18. Андрейко С.С., Иванов О.В., Литвиновская Н.А. Прогнозирование и предотвращение газодинамических явлений из почвы при проходке подготовительных выработок в подработанном массиве соляных пород. - Пермь: изд-во ПНИПУ, 2015. - 159 с.

19. Литвиновская Н.А. Газоносность и газодинамические характеристики пород почвы горных выработок в надработанном соляном массиве // Актуальные проблемы повышения эффективности и безопасности эксплуатации горношахтного и нефтепромыслового оборудования: материалы II Междунар. науч.-практ. конф. «Горная и нефтяная электромеханика - 2015» / ПНИПУ. - Пермь, 2015. - Т. 1. - С. 136-142.

20. Литвиновская Н.А. Газоносность и газодинамические характеристики пород почвы при слоевой выемке третьего калийного пласта в условиях рудников ОАО «Беларуськалий» // Стратегия и процессы освоения георесурсов: сб. науч. тр. Вып. 14 / ГИ УрО РАН. - Пермь, 2016. - С. 315-317.

21. Андрейко С.С. Предотвращение газодинамических явлений из почвы горных выработок в условиях применения различных вариантов столбовой системы разработки Третьего калийного пласта на рудниках ОАО «Беларуськалий» // Стратегия и процессы освоения георесурсов: сб. науч. тр. Вып. 15 / ГИ УрО РАН. - Пермь, 2017. - С. 341-345

22. Геологическое заключение по оценке состояния водозащитной толщи на шахтных полях ПАО «Уралкалий»: отчет о НИР / ГИ УрО РАН; рук. И.И. Чайковский. - Пермь, 2016. - 28 с.

23. Андрейко, С.С., Шаманский Г.П., Лаптев Б.В. Многомерные статистические критерии классификации газодинамических явлений на рудниках Верхнекамского месторождения калийных солей // Физикотехнические проблемы разработки полезных ископаемых. - 1985. - № 1. - С.85-94.

\title{
ОБЗОР АВАРИЙНЫХ СИТУАЦИЙ ПРИ СТРОИТЕЛЬСТВЕ ШАХТНЫХ СТВОЛОВ СПЕЦИАЛЬНЫМ СПОСОБОМ ИСКУССТВЕННОГО ЗАМОРАЖИВАНИЯ ГОРНЫХ ПОРОД
}

\author{
О.С. ПАРШАКОВ \\ Горный институт УрО РАН, г. Пермь
}

\begin{abstract}
Аннотация: В работе представлен краткий обзор аварийных ситуаций, возникающих при строительстве шахтных стволов в сложных гидрогеологических и геологических условиях. Приведены основные причины появления аварий и осложнений при ведении горных работ в условиях замораживания породного массива. Отмечено, что тенденция освоения месторождений, залегающих в сложных гидрогеологических условиях, продолжает возрастать. Несмотря на накопленную научную базу и высокий уровень развития технологии производства работ по замораживанию массива пород осложнения, которые обнаруживаются при проходке шахтного ствола через обводненные горные породы, в полной мере исключить невозможно. В результате для снижения риска возникновения аварийных ситуаций предложено применять автоматизированную систему термометрического контроля замораживаемого участка породного массива. Система контроля позволит обеспечить безопасность строительства шахтных стволов способом искусственного замораживания горных пород за счет повышения точности определения параметров состояния ледопородного ограждения.

Ключевые слова: искусственное замораживание пород; ледопородное ограждение; строительство шахтных стволов; аварийные ситуации; система термометрического контроля.

Строительство шахтных стволов способом искусственного замораживания горных пород в сложных гидрогеологических и геологических условиях нередко сопровождается осложнениями и серьезными авариями, последствия которых могут привести к затоплению горной выработки, а следовательно и к реальной угрозе ее полной потери. За длительный период применения искусственного замораживания пород (начиная с 1883 г.) в существующей литературе [1-8] приводится множество примеров возникновения аварийных ситуаций при освоении месторождений полезных ископаемых.
\end{abstract}

